\title{
COUPLING BETWEEN NEURONS OF THE DEVELOPING RAT NEOCORTEX ${ }^{1}$
}

\author{
B. W. CONNORS, ${ }^{2}$ L. S. BENARDO,${ }^{3}$ AND D. A. PRINCE \\ Department of Neurology, Stanford University School of Medicine, Stanford, California 94305 \\ Received August 5, 1982; Revised October 11, 1982; Accepted October 15, 1982
}

\begin{abstract}
We have estimated the prevalence of coupling between neurons of the rat neocortex during postnatal development. Single intracellular injections of the fluorescent dye Lucifer Yellow $\mathrm{CH}$ resulted in dye coupling among $70 \%$ of neurons from 1 to 4 days of age. Dye coupling dropped to 30 to $40 \%$ by 10 to 18 days and occurred in $20 \%$ of injected adult neurons. The number of neurons per dye-coupled aggregate also decreased. Whereas three to seven coupled neurons were common in cortex of 1 to 4 days, aggregates of more than two neurons were exceptionally rare in adults. The frequency of dye coupling did not vary systematically with cortical depth at any age. When chemical synaptic activity was blocked, most 4-day neurons exhibited short latency antidromically evoked depolarizations which were relatively insensitive to repetitive activation and membrane polarization. These depolarizations may represent electrotonically conducted spikes from coupled neurons. No such potentials were found in adult neurons. The results suggest that neuronal coupling is extensive in immature rat neocortex, but that coupling declines at a time just before the numbers of chemical synapses increase most rapidly.
\end{abstract}

The morphology of cellular development in the neocortex is well described. Autoradiographic investigations have revealed that neuroblasts migrate radially from their origins in the deep ventricular germinal zone to form the cortical plate, with each cell assuming a final position superficial to that of its predecessors (Angevine and Sidman, 1961; Berry and Rogers, 1965; Hicks and D'Amato, 1968). Studies using the Golgi technique have meticulously charted the ensuing progression of complexity and diversity of neuronal shapes (e.g., Ramon y Cajal, 1911; Eayrs and Goodhead, 1959; Miller, 1981). However, very little is known about the types of neuronal interactions which must certainly occur during cortical development nor the specific roles these may play in the genesis and function of immature neocortical circuits. With Golgi-electron microscopic methods, it has become possible to document the ontogeny of structurally defined synaptic connections between cortical neurons (Parnavelas et al., 1978; Miller and Peters, 1981), but the data are still quite sparse.

\footnotetext{
'We wish to thank Ms. Cheryl Joo for manuscript preparation. This work was supported by National Institutes of Health Grant NS 06477 (D. A. P.) and a Lennox Fellowship from the American Epilepsy Society (B. W. C.)

${ }^{2}$ To whom correspondence should be addressed.

${ }^{3}$ Present address: College of Physicians and Surgeons of Columbia University, New York, NY 10032.
}

One form of cell-to-cell communication which is particularly prominent in early development is that subserved by the low resistance intermembranous channels which often aggregate to form gap junctions (Loewenstein, 1981). In fact, as pointed out by Bennett et al. (1981), the presence of this form of intercellular coupling has been observed in every early embryo which has been studied, from annelids to mammals. The developmental distribution of coupling in both space and time may be quite specific, although the electrical and/or chemical communicative roles which it serves are very poorly understood. Some of the most intriguing examples of developmental changes in coupling have been observed in nonmammalian nervous systems (e.g., Dixon and Cronly-Dillon, 1972; Lo Presti et al., 1974; Goodman and Spitzer, 1979). Examples in developing mammalian nervous systems are more poorly documented. Motoneurons of the newborn rat spinal cord appear to be extensively coupled to one another (Fulton et al., 1980), but it is not clear whether the coupling changes with maturity.

Morphological evidence in adult primates (Sloper, 1972; Sloper and Powell, 1978; Smith and Moskovitz, 1979) and adult rats (Peters, 1980), as well as physiological data from adult guinea pigs (Gutnick and Prince, 1981), suggests that electrical coupling may have a significant role in the function of mature neocortex. To assess the prevalence of coupling in developing neocortex we have used intracellular injections of the junction- 
permeable fluorescent dye Lucifer Yellow CH (Stewart, 1978) and indirect electrophysiological tests. These results have appeared in abstract form (Benardo et al., 1982).

\section{Materials and Methods}

All experiments were performed in vitro on slices of neocortex obtained from albino rats (Sprague-Dawley). Animals ranged in age from 1 day ( 0 to $24 \mathrm{hr}$ following time of birth) to adulthood ( $>60$ days), and ages were not controlled for gestation time.

Techniques for maintaining neocortical slices in vitro have been previously described (Connors et al., 1982). Animals were decapitated and their brains rapidly removed and placed in ice-cold Ringer solution. Using a scalpel, a block of tissue was dissected from the sensorimotor area, or its presumed precursor. Slices of $500-\mu \mathrm{m}$ nominal thickness were cut in the coronal plane on a Mcllwain tissue chopper and immediately placed in a recording chamber maintained at $36 \pm 1^{\circ} \mathrm{C}$. Slices were continuously superfused with solution saturated with $95 \% \mathrm{O}_{2} 5 \% \mathrm{CO}_{2}$.

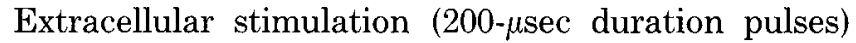
was applied via a sharpened monopolar tungsten electrode placed in cortical layers deep to the recording site. Intracellular recordings were obtained with microelectrodes pulled from 1-mm thin walled capillary tubing (Frederick Haer, Inc.). Electrodes were filled with either $4 \mathrm{~m}$ potassium acetate ( 40 to 50 megohms) or a $5 \%$ solution of Lucifer Yellow $\mathrm{CH}$ (Aldrich Chemical Co., Inc.) in distilled water ( 150 to 250 megohms). All recordings and dye injections reported here were obtained from neurons, identified physiologically by the presence of action potentials, evoked synaptic potentials, and relatively high input resistances. Glia were encountered in older cortices but were easily distinguished by standard criteria previously confirmed in the neocortical slice preparation (Gutnick et al., 1981). Dye was injected into neurons via a bridge circuit by applying 750-msec hyperpolarizing current pulses of 2 to $4 \mathrm{nA}$ at a rate of $1 \mathrm{~Hz}$. The injection period was terminated at $5 \mathrm{~min}$ or if the membrane potential dropped below about $20 \mathrm{mV}$. The current intensity and duration of each injection were recorded. Dye injections were limited to four to five per slice and were spaced far enough apart that specific identification of each site was unambiguous after processing the tissue. Following dye injection, slices remained in the recording chamber for a minimum of $30 \mathrm{~min}$. Slices were fixed overnight in $4 \%$ buffered formalin $\left(3^{\circ} \mathrm{C}\right)$, dehydrated, cleared, and whole mounted for viewing under epifluorescence (Stewart, 1978).

\section{Results}

Dye coupling. Injection of Lucifer Yellow $\mathrm{CH}$ into adult neocortical neurons most often stained single pyramidal-shaped cells (Fig. $1 A$ ) and occasional single nonpyramidal cells. In $20 \%$ of the successfully recovered injections $(n=46)$, however, more than one cell was stained following a single intracellular recording. The majority of these dye-coupled aggregates consisted of pairs of cells; in only one case were three cells stained and never more than three. Somata of stained cells were located from 150 to $1600 \mu \mathrm{m}$ below the pia, and the laminar distribution of dye-coupled neurons was coextensive with that of uncoupled neurons. The presence of neuronal dye coupling in adult rat neocortex confirms similar observations in the homologous part of adult guinea pig neocortex (Gutnick and Prince, 1981; L. S. Benardo, B. W. Connors and D. A. Prince, unpublished experiments). There are quantitative differences, however. In guinea pigs, coupling resulted from $44 \%$ of the injections, and coupled neurons were usually confined to superficial cortical layers ( $<400 \mu \mathrm{m}$ deep) (Guinick and Prince, 1981). Most strikingly, coupled aggregates in the guinea pig commonly consisted of three to six neurons, in contrast to the overwhelming incidence of coupled pairs in the rat.

When Lucifer Yellow $\mathrm{CH}$ was injected into cortical neurons 10 to 18 days of age (Fig. $1, B$ and $C$ ), the incidence of dye coupling was slightly greater than in the adult (28 to $40 \%$ ). Coupled aggregates still consisted primarily of pairs, but a few groups of three to six neurons were encountered. In contrast, neuronal dye coupling in cortices from 1- to 4-day animals was quite common. Figures 2 and 3 illustrate several examples of the staining patterns which were recovered. Many cells appeared to be immature forms of pyramidal neurons (Fig. 2, $A$ and $B$; Fig. 3., $A$ and $C$ ), whereas others were more stellate shaped (Fig. $3 B$ ). In almost every case, the intensity of staining was great enough to show an overlap of dendritic fields and, in some pyramidal cells, the extension of adjacent apical dendrites into apparent bundles (cf. Roney et al., 1979). Because dendrites usually coursed near the somata of coupled cells also, it is impossible to state whether the sites of coupling were dendro-dendritic or dendro-somatic. The average size of each neuronal aggregate was also greater in very immature neocortex. Coupled groups of 3 to 10 neurons were often recovered, although pairs of cells were still the most prevalent group size. As with the more mature neocortex, coupled neurons were coextensive in subpial depth (150 to $750 \mu \mathrm{m})$ with uncoupled neurons. However, only coupled cells were encountered at the most superficial depths (50 to 150 $\mu \mathrm{m})$.

Figure 4 graphically illustrates the developmental course of the incidence of dye coupling. Because the occurrence of coupling dropped dramatically between 4 and 10 days, data were grouped to illustrate the distribution of cells per coupled aggregate (Fig. 5). Thus, within the 10 days following birth, both the percentage of cells coupled and the number of cells per coupled group decreased.

As in the adult guinea pig cortex (Gutnick and Prince, 1981), coupled rat neurons of all ages were often arranged in vertical arrays (Fig. $2, A$ and $B$; Fig. $3 A$ ). Along the radial axis intersomatic distances ranged from less than one cell radius (i.e., overlapping) up to 200 to $300 \mu \mathrm{m}$, whereas the lateral spread of cell bodies in a group rarely exceeded $50 \mu \mathrm{m}$ and was usually less. There was no consistent change in either the radial or lateral extent of cell aggregates during development.

Because estimates of the amount of injected dye (calculated from the current.time product) were variable between injections, we were concerned that the degree 

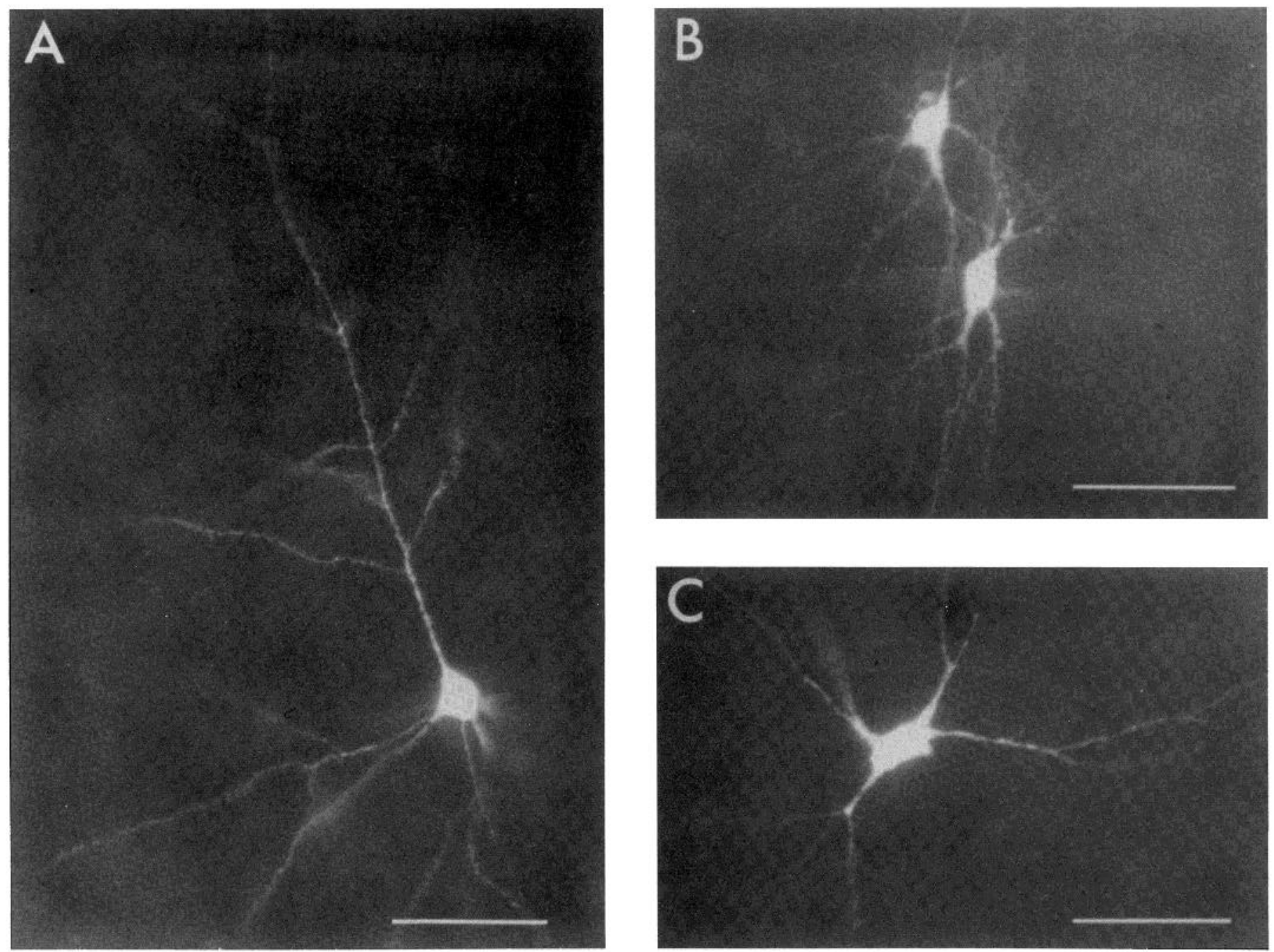

Figure 1. Lucifer Yellow-stained neocortical neurons. A, Single pyramidal neuron of adult cortex. $B$, Pair of dye-coupled neurons from deep layers of 10-day-old cortex. $C$, Single spindle-shaped nonpyramidal cell from 10-day cortex. Calibration bars $=50 \mu \mathrm{m}$.

of dye coupling might be a function of the quantity of dye injected. However, there was no correlation between the estimated amount of dye injected and the number of coupled cells recovered when data from a given age (and thus from cells of similar volumes) were pooled. When control ejections of dye were made extracellularly at all ages, there was usually no staining recovered after processing the tissue. Occasionally a single faintly stained neuron could be discerned, but this was not age dependent.

Electrophysiological evidence for coupling. The most direct test for the presence of electrical coupling between cells is the demonstration that passage of current into one cell appropriately alters the membrane potential of the coupled cell by a pathway other than the extracellular space or a chemically mediated synapse (Bennett, 1977). The technical difficulties inherent in simultaneously recording from pairs of immature neocortical cells, together with the low probability of blindly impaling two coupled cells (cf. MacVicar and Dudek, 1981; Knowles and Schwartzkroin, 1981), prompted us to concentrate our efforts on a less direct test. This entailed antidromically activating a group of neurons while recording intracellularly from a single neuron. With chemical synaptic activity suppressed, action potentials should, given sufficiently high electrical coupling coefficients, be propagated electrotonically from coupled neighbors to the recorded cell (Bennett, 1977).

Although intracellular recordings were obtained from 1-day cortical neurons, most of the data reported here were made from 4-day neurons because of their greater stability. Using potassium acetate electrodes, well impaled neurons in normal medium had membrane potentials comparable to those of adult neocortical neurons in vitro (Connors et al., 1982) and input resistances ranging above 100 megohms. Current injections revealed a prominent delayed rectification, and high threshold action potentials could be evoked (Fig. $6 A$ ). Stimulation in the deeper layers usually elicited long lasting (100- to 200msec) EPSPs (Fig. $6 B$ ), which proved to be very sensitive to repetitive activation, i.e., marked attenuation occurred at stimulation rates greater than $0.5 \mathrm{~Hz}$. In many cells an apparent antidromic spike could be evoked, although it usually failed to invade the soma completely (Fig. $6 B$ ). 

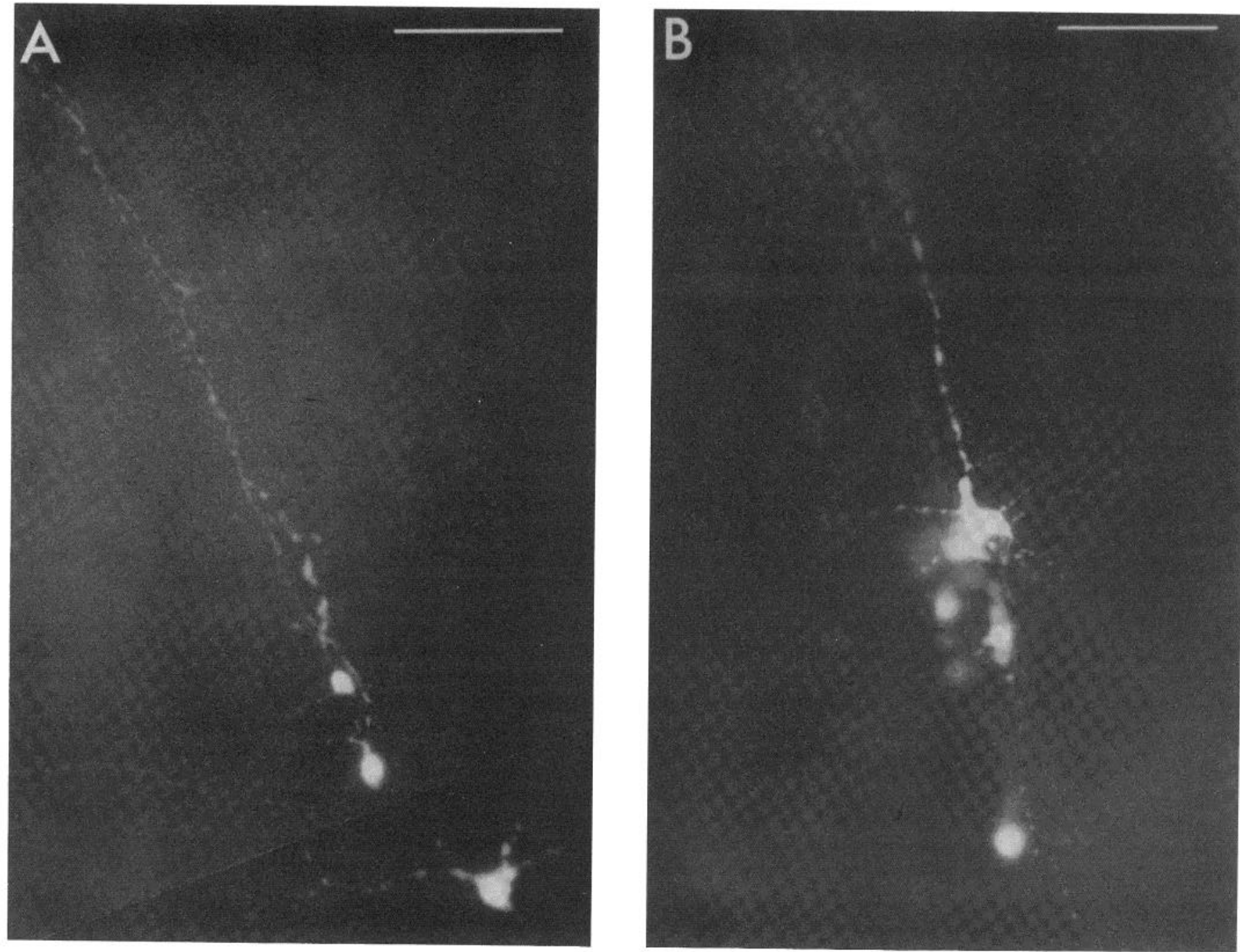

Figure 2. A, Dye coupling between three neurons of 1-day cortex. The apical dendrites of each cell intertwined as they headed toward the pia (top left). Photograph is a composite of two planes of focus. $B$, Neurons of 4 -day cortex. In this example seven neurons were stained from a single dye injection. Most cells are out of the plane of focus. Calibration bars $=50 \mu \mathrm{m}$.

When polarized with current passed through the recording electrode, the antidromic spike could be blocked and the EPSP amplitude grew with hyperpolarization and diminished with depolarization, although reversals could not be demonstrated under these conditions.

When slices were bathed in a medium containing $1 \mathrm{~mm}$ $\mathrm{Ca}^{2+}$ plus $3 \mathrm{~mm} \mathrm{Mn}^{2+}$ for 30 min or more, long duration chemically mediated EPSPs were abolished, as noted previously in adult guinea pig cortex (Gutnick and Prince, 1981). Neurons were still readily impaled, and in 12 of 15 neurons of 4-day-old cortex it was possible to elicit subthreshold depolarizing potentials antidromically (Fig. $7 A$ ). In most cells these consisted of one to three separate all-or-none components, each with a discrete threshold. The neuron illustrated in Figure $7 A$ is unusual in having five to six components, with varying latencies. The duration of the antidromic events was shorter than the EPSPs in normal medium and typically lasted 20 to 60 msec. Unlike chemically mediated synaptic potentials, these events would withstand short periods of stimulation at rates up to $20 \mathrm{~Hz}$ without attenuation. The discrete and long (1.5- to 4.5-msec) latencies of antidromic potentials indicate that they do not arise from direct excitation of dendrites or somata. When electrodes were withdrawn from the neurons, extracellular antidromic field potentials consisted of small $(\leqslant 0.5 \mathrm{mV})$ positive-negative events which lasted 2 to 4 msec. Thus, the intracellularly recorded potentials are not significantly changed when the field potentials are subtracted from them.

When polarized, antidromic potentials were either unaffected or slightly decreased in amplitude (Fig. $7 B$ ). When changes did occur, they could not be explained by measurable changes in membrane rectification. It was sometimes possible to abolish one or more components of the responses by hyperpolarization, but in only one cell was the antidromic potential completely blocked. Such blockable components may have been antidromically conducted spikes from the axon of the recorded neuron or electrotonic potentials from neurons so tightly coupled that current injected through the recording electrode was sufficient to block spike invasion of the coupled cell. The relative voltage insensitivity of the remaining portions of the antidromic potentials suggests that they are not chemically mediated synaptic potentials, and it is consistent with the concept that they are electrotoni- 

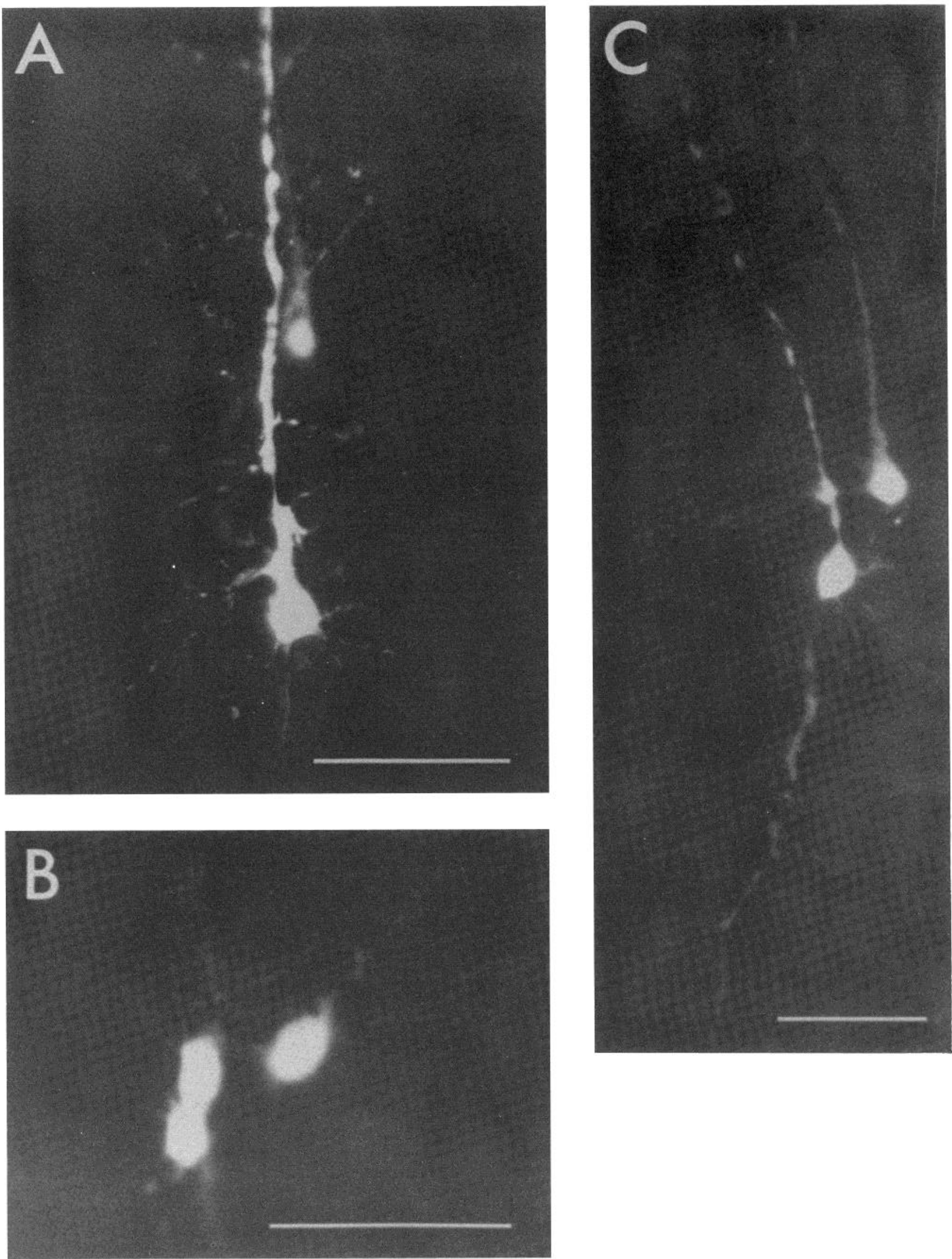

Figure 3. Dye coupling in 4-day cortical neurons. A, Large immature pyramidal cell with smaller, less densely stained, pyramidal cell located adjacent to its apical dendrite. $B$, Three dye-coupled nonpyramidal cells located $500 \mu \mathrm{m}$ from pial surface. $C$, Dyecoupled cells located $225 \mu \mathrm{m}$ from pia. Both had apical dendrites which extended into layer I; cell on left had axon which could be traced to deepest layers. Calibration bars $=50 \mu \mathrm{m}$ in $A$ and $B ; 25 \mu \mathrm{m}$ in $C$. 
cally conducted from neighboring coupled neurons. The long duration of the antidromic potentials relative to full action potentials is consistent with the low pass filter characteristics of electrotonic junctions.

Another indirect test of electrical coupling is the demonstration that the suspected coupling potential cannot be collided with a preceding orthodromic impulse elicited in the impaled neuron (Baker and Llinas, 1971; Gutnick and Prince, 1981; Taylor and Dudek, 1981). Application of this approach in 4-day cortex was hampered by the high thresholds of the immature neurons, which appeared to be even higher when slices were bathed in $\mathrm{Mn}^{2+}$-containing solution. Nevertheless, in two $\mathrm{Mn}^{2+}$ treated neurons it was possible to show that antidromic

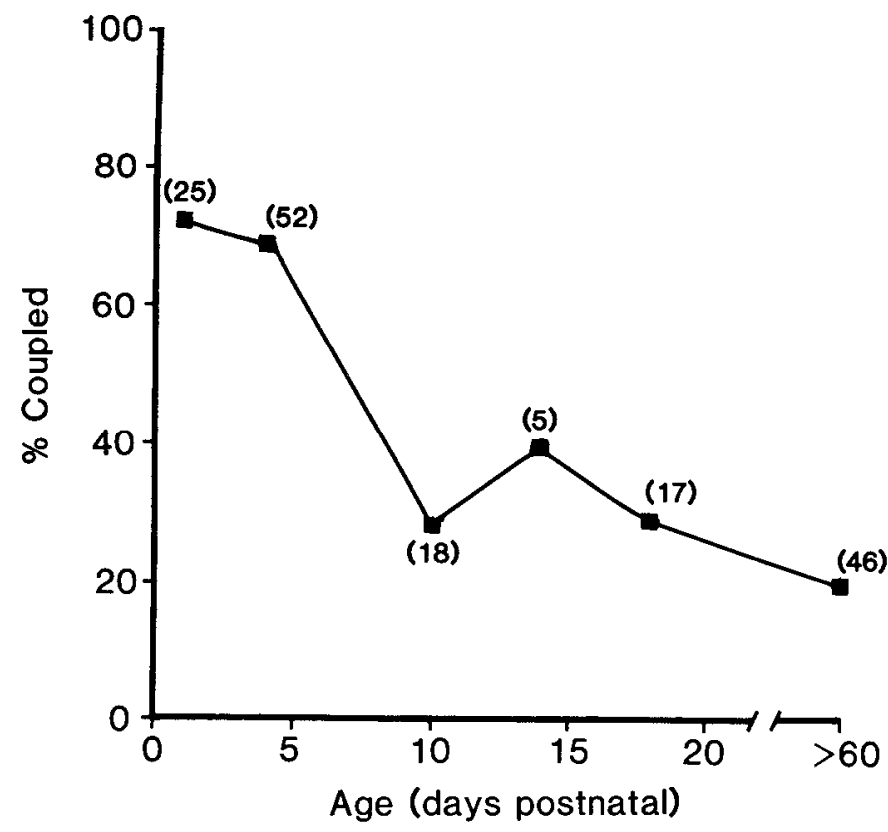

Figure 4. Incidence of dye coupling as a function of age. The ordinate is the percentage of successful Lucifer Yellow injections which yielded more than one stained neuron. Numbers in parentheses stand for the number of successful dye injections for each point. potentials persisted even when the interval between the preceding orthodromic spike and the antidromic potential was sufficiently short to have produced collision (i.e., $<2 L+R$, where $L$ is the antidromic potential latency and $R$ is the estimated refractory period of the axon, which may be several milliseconds in immature central axons; cf., Foster et al., 1982). In another neuron (Fig. $7 C$ ) the antidromic potential had two components with different thresholds and latencies. When preceded by an orthodromic spike the slower, presumably axonal, component could be shown to collide, leaving the faster,

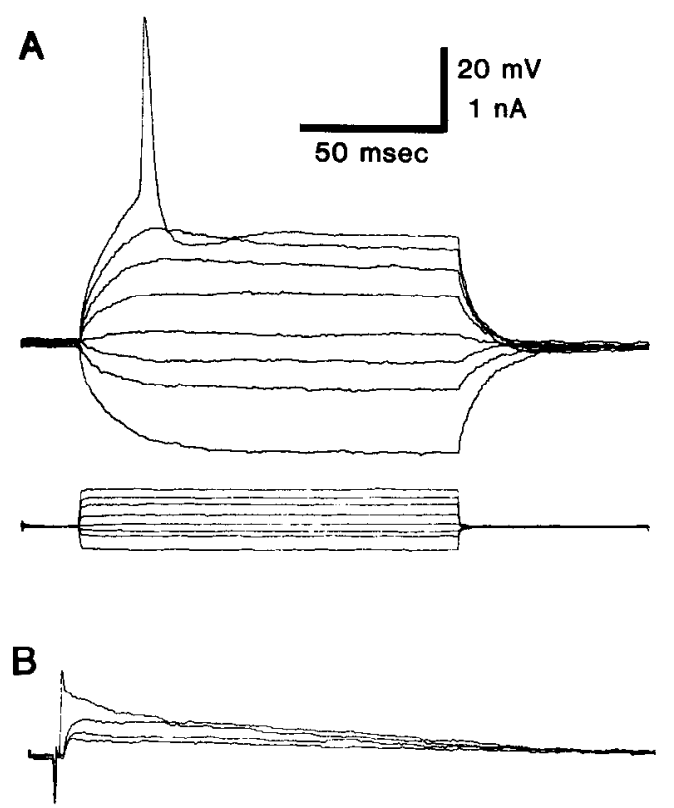

Figure 6. Intracellular recordings from 4-day neuron. $A$, Superimposed voltage (upper) and current (lower) traces during intracellular current injection. Input resistance in the hyperpolarizing direction was about 100 megohms. Largest current pulse in the depolarizing direction evoked an action potential. $B$, Focal stimulation to deep cortical layers evoked long EPSPs (different cell). Superimposed traces obtained with increasing stimulus intensity. Highest intensity evoked a short latency allor-none antidromic spike.

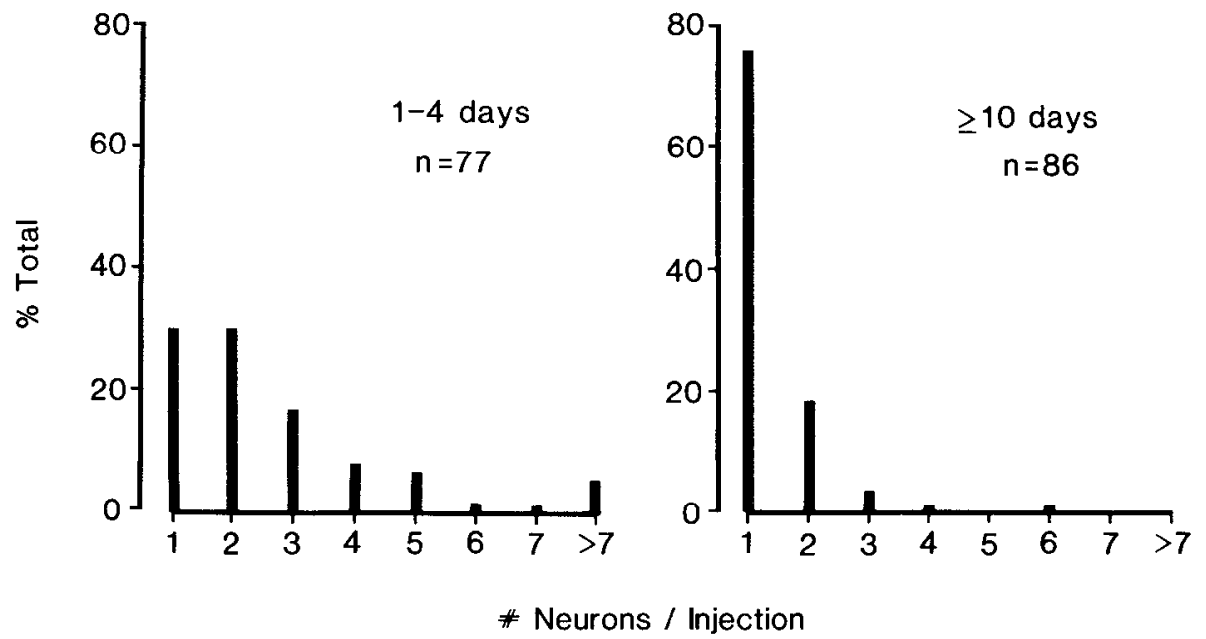

Figure 5. Frequency histograms of the number of stained neurons per successful dye injection. Data have been grouped from cortices 1 to 4 days of age (left) and those 10 days or older (right). 

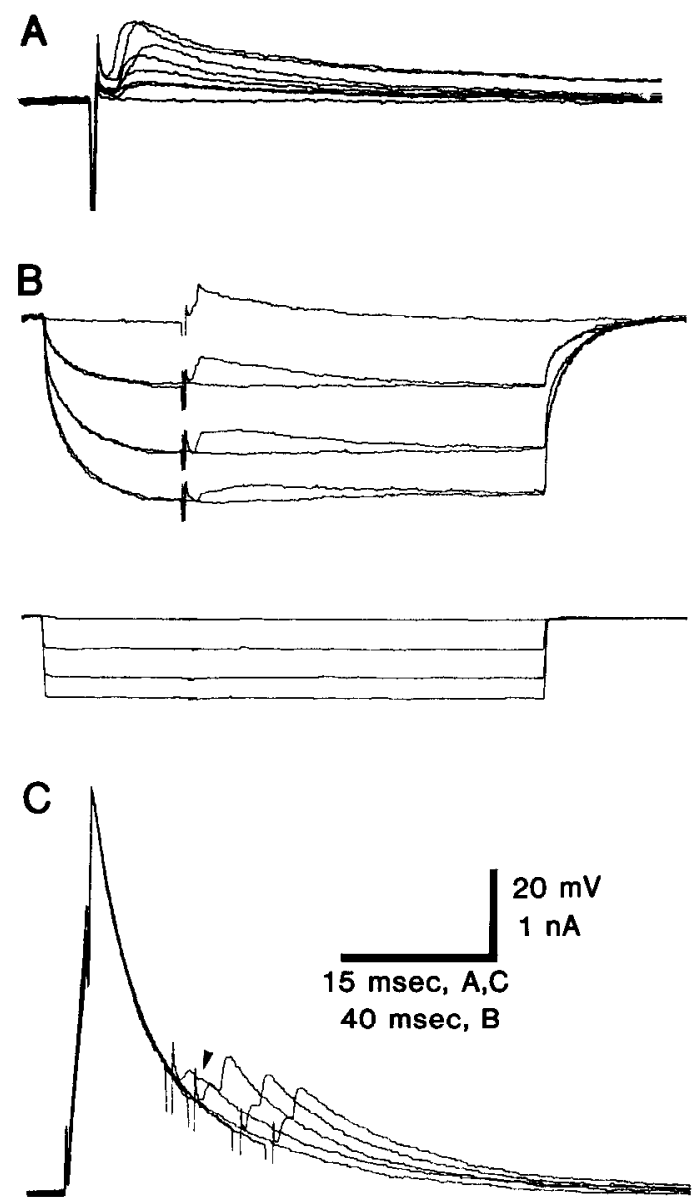

Figure 7. $\mathrm{Mn}^{2+}$-resistant antidromically evoked potentials in 4-day cortical neurons (three different neurons). $A$, Stimulus applied to deep layers, increasing intensity. Five to six discrete depolarizing events were evoked at relatively high thresholds. $B$, When antidromic potentials were superimposed on hyperpolarizing current pulses, they showed diminished amplitude despite constancy of membrane conductance. $C$, Partial collision of antidromic potentials. Initial orthodromic potential was evoked with a short intracellular current pulse, and antidromic potentials were evoked at progressively shorter interstimulus intervals (double vertical lines are stimulus artifacts). At longer intervals there were two discrete components to the potential; at the short interval the second component was blocked ( $a r$ row), leaving the short latency component intact.

presumably coupling, component intact (Fig. 7C, arrow). In two other neurons most or all of the antidromic potentials could be collided and thus may have represented partial invasion of axonal spikes from the same cell. Alternative interpretations of both the positive and negative results are possible (Taylor and Dudek, 1982). For example, if electrical coupling ratios are high, the orthodromic spike in a collision test might occlude the coupling potentials because it would trigger spikes in the coupled neurons. Conversely, low coupling ratios would result in antidromic coupling potentials too small to detect. A low safety factor for antidromic propagation would also preclude the electrotonic propagation of these potentials into neighboring neurons.

Of 15 recordings from adult neurons bathed in $\mathrm{Mn}^{2+}$. containing solution, six showed no response to intense stimulation of deeper layers, whereas in eight it was possible to elicit an antidromic action potential which fully or partially invaded the site of recording. Antidromic spikes had single discrete thresholds of stimulus intensity and could be blocked by hyperpolarization or collision with an orthodromic spike. In one neuron antidromic stimulation generated two subthreshold components, both of which were eliminated in an all-or-none fashion when the membrane was hyperpolarized 10 to 20 $\mathrm{mV}$ from resting potential. These may have been antidromically conducted spikes from two axon collaterals of the recorded neuron.

\section{Discussion}

We have presented two types of evidence for a relatively high incidence of electrical coupling among immature rat neocortical neurons: the large percentage of Lucifer Yellow-injected cells which are dye coupled, and the frequent observations of $\mathrm{Mn}^{2+}$-resistant, antidromically evoked subthreshold depolarizations. The results of similar experiments in more mature rat neocortex stand in stark contrast. The incidence of dye coupling was very much lower, and there were virtually no clear examples of possible coupling potentials when chemical synapses were suppressed. The latter finding is somewhat surprising, considering the significant degree of dye coupling in adults, but may indicate that whatever neuronal coupling does remain in the mature rat cortex is either electrically weak or so strong that the coupled cells effectively function as one. Such a high electrical coupling coefficient would seem unlikely with a dendro- or soma-dendritically located coupling site, but further studies are necessary to clarify this issue. Nevertheless, the developmental trend in both the dye coupling and electrophysiology is quite similar: both indicate a large decrease in neuronal coupling between birth and 10 days.

An important morphological correlate of these data would be the identification of neuronal gap junctions with electron microscopy. Although these have not yet been described for immature rat neocortex, such specializations have been seen in frontal cortex of adult rats (Peters, 1980), as well as auditory (Smith and Moskovitz, 1979) and sensorimotor cortex of adult primates (Sloper, 1972; Sloper and Powell, 1978). On the earlier end of the developmental scale, interdendritic gap junctions have been identified in neocortex of fetal sheep (Mollgard and Moller, 1975) and humans (Mollgard, 1975) and on the ventricularly directed processes of cortical neuroblasts in embryonic mice (Shoukimas and Hinds, 1978). The difficulties involved in anatomically visualizing gap junctions among a complex neuropil make it very possible that their apparent absense in the developing rat is simply a matter of experimental neglect. Alternatively, functional coupling can sometimes persist in cellular systems devoid of organized gap junctions (e.g., Williams and De Haan, 1981), presumably because the intermembranous channels exist at a low spatial density.

The detection of coupled cells by the spread of a dye molecule depends critically upon several factors (cf. Bennett et al., 1978). The amount of dye injected, the junctional and nonjunctional dye permeabilities, the rate of dye destruction, the volumes of the coupled cells, and the incubation time preceding fixation will help to determine 
whether the fluorescence level in all cells of a coupled aggregate appear above the detection level. If these factors were held constant, one could expect to have a reliable indicator of the relative degree of coupling between different cell populations. However, in a developing system such constancy is unlikely. Nevertheless, several considerations lead us to believe that our observed degrees of dye coupling are valid.

Stewart (1978) has demonstrated that the cell membrane permeability of Lucifer Yellow is extremely low, allowing dye to leak from cells only over periods of many hours to days. Cytoplasmic diffusion, however, seems to be relatively unimpeded, and dye passage between cells known to be electrically coupled by gap junctions occurs rapidly (i.e., over minutes) (Spray et al., 1979; Schuetze and Goodenough, 1982). These properties are not likely to change significantly during cortical development. Of more concern, however, is the large change in neuronal volume which occurs postnatally (Miller, 1981). If the amount of dye per injection was kept constant, its cytoplasmic dilution would be increased in large, mature cells, allowing the possibility that coupled cells would be less detectable. In the ideal steady state experiment, the amount of dye per unit volume of coupled cytoplasm would be kept relatively constant, but uncertainties regarding cell volumes (soma + dendrites) and the actual amount of dye delivered at each intracellular injection make such a controlled experiment unfeasible. However, the staining intensity of coupled neurons was often quite uniform, suggesting that chemical coupling coefficients (as distinct from electrical coupling coefficients) were quite high under the conditions of long equilibration times. This was especially true of older neurons (i.e., $>10$ days), where more dye could be injected and the number of cells per aggregate were generally smaller. Data also indicated that within a given age, and thus among neurons of similar volume, these was no correlation between the amount of injected dye and the number of coupled cells.

The developmental sequence of electrical coupling we have described may faithfully represent the situation which obtains for the neocortex in situ; alternatively, the procedure of slicing and incubating the tissue may induce the formation of cytoplasmic bridging or even de novo synthesis of gap junctions. Although our data do not address this issue, dye injections into hippocampal pyramidal cells yielded similar incidences of coupling in vivo and in vilro (MacVicar and Dudek, 1980; MacVicar et al., 1982). The possibility remains that immature tissue is more labile in its response to the trauma of the isolation process.

A related, and less soluble, question is whether the injection electrode itself induced the coupling by damaging and fusing closely apposed dendrites and/or somata (cf., Kaneko et al., 1981). This seems improbable because the density of dendritic and axonal arborizations is substantially lower in immature cortex than in that of adults (Eayrs and Goodhead, 1959), whereas the incidence and number of neurons per dye-coupled aggregate decreased dramatically with age. Moreover, most of the coupled cells had well separated somata, making it unlikely that the electrode was able to slip unobserved from one neuron to another during the injection of dye or during electrode withdrawal (cf., Andrew et al., 1982). Some of the neurons within a single dye-filled aggregate also displayed distinct variations in fluorescence intensity. This would be consistent with the limited rate of dye diffusion one might expect between weakly coupled cells, rather than cells with syncytially fused membranes. Nevertheless, the possibility that neocortical dye coupling is an experimental artifact still remains. In hippocampal CA1 pyramidal cells, discrepancies between dye coupling and electrophysiological data have led Knowles et al. (1982) to conclude that at least some of the multiple-cell stains in that area are spurious. In the neocortex, however, alternative explanations would have to account for the wide variations in dye coupling which occur during stages of maturity, between different architectonic areas (M. J. Gutnick, personal communication), and between species (cf., this study and that of Gutnick and Prince, 1981).

The roles played by intercellular coupling in development are still largely speculative. The aqueous channels assumed to form the connection can easily pass small inorganic ions; this property is exploited by a variety of neuronal systems to produce functional electrical synapses (Bennett, 1977). Yet channel permeability extends to much larger molecules (Finbow and Pitts, 1981; Schwarzmann et al., 1981) and the intriguing correlative evidence in developing systems suggests that gap junctions serve as a pathway for organic or inorganic informational substances (for references see Bennett et al., 1981). Our evidence for the importance of cellular coupling in the developing neocortex is similarly correlative. At birth, rat neocortex contains only a very few ultrastructurally defined chemical synapses, but the absolute number increases many-fold between postnatal days 10 and 30 (Eayrs and Goodhead, 1959; Aghajanian and Bloom, 1967; Armstrong-James and Johnson, 1970; Wolff, 1978). In rat visual cortex, lateral geniculate afferents begin to form synapses between postnatal days 6 and 8 (Lund and Mustari, 1977). Our data show that dye coupling is most prevalent at 1 to 4 days and falls to nearly adult levels by about 10 days. Thus, loss of neuronal coupling may coincide with, or slightly precede, the explosive synaptogenesis of this formative period. The electrical recordings obtained when chemical synapses were suppressed suggest that the immature coupling coefficients may be high enough to effect significant electrical communication. This might partially substitute for the weakness of intrinsic chemical synaptic connectivity in the rat neonate and may have a role in the synchronization of neonatal cortical discharges (cf., Crain, 1952; Armstrong-James and Williams, 1963; Crain and Bornstein, 1974). Inasmuch as the large decrease in coupling also occurs before most extrinsic cortical connections have formed (Lund and Mustari, 1977; Wise and Jones, 1978), it is unlikely that coupling in very immature cortex is behaviorally significant. Rather, the coupling may have a role in the formation of neuronal connectivity by facilitating some developmentally crucial signal, either electrical or chemical. 


\section{References}

Aghajanian, G. K., and F. E. Bloom (1967) The formation of synaptic junctions in developing rat brain: A quantitative electron microscopic study. Brain Res. 6: 716-727.

Andrew, R. D., C. P. Taylor, R. W. Snow, and F. E. Dudek (1982) Coupling in rat hippocampal slices: Dye transfer between CA1 pyramidal cells. Brain Res. Bull. 8: 211-222.

Angevine, J. R., and R. L. Sidman (1961) Autoradiographic study of cell migration during histogenesis of cerebral cortex in the mouse. Nature 192: 766-768.

Armstrong-James, M., and B. Johnson (1970) Quantitative studies of postnatal changes in rat superficial motor cerebral cortex. Z. Zellforsch. Mikrosk. Anat. 110: 559-568.

Armstrong-James, M. A., and T. D. Williams (1963) Post-natal development of the direct cortical response in the rat. J Physiol. (Lond.) 168: 19-20P.

Baker, R., and R. Llinas (1971) Electrotonic coupling between neurons in the rat mesencephalic nucleus. J. Physiol. (Lond.) 212: 45-63.

Benardo, L. S., B. W. Connors, and D. A. Prince (1982) Interneuronal coupling in the developing rat neocortex. Soc. Neurosci. Abstr. 8: 437.

Bennett, M. V. L. (1972) Properties of electrotonic junctions between embryonic cells of Fundulus. Dev. Biol. 29: 419-435.

Bennett, M. V. L. (1977) Electrical transmission: A functional analysis and comparison with chemical transmission. In $\mathrm{Cel}$ lular Biology of Neurons, Vol. I, Sect. I, Handbook of Physiology, The Nervous System, E. R. Kandel, ed., pp. 357-416, Williams \& Wilkins, Baltimore.

Bennett, M. V. L., M. E. Spira, and D. C. Spray (1978) Permeability of gap junctions between embryonic cells of Fundulus: A reevaluation. Dev. Biol. 65: 114-125.

Bennett, M. V. L., D. C. Spray, and A. L. Harris (1981) Electrical coupling in development. Am. Zool. 21: 413-427.

Berry, M., and A. W. Rogers (1965) The migration of neuroblasts in the developing cerebral cortex. J. Anat. 186: 473490.

Connors, B. W., M. J. Gutnick, and D. A. Prince (1982) Electrophysiological properties of neocortical neurons in vitro. J. Neurophysiol. 48: 1302-1320.

Crain, S. M. (1952) Development of electrical activity in the cerebral cortex of the albino rat. Proc. Soc. Exp. Biol. Med. 81: 49-51.

Crain, S. M., and M. B. Bornstein (1974) Early onset in inhibitory functions during synaptogenesis in fetal mouse brain cultures. Brain Res. 68: 351-357.

Dixon, J. S., and J. R. Cronly-Dillon (1972) The fine structure of the developing retina in Xenopus laevis. J. Embryol. Exp. Morphol. 28: 659-666.

Eayrs, J. T., and B. Goodhead (1959) Postnatal development of the cerebral cortex of the rat. J. Anat. 93: 385-402.

Finbow, M. E., and J. D. Pitts (1981) Permeability of junctions between animal cells. Intercellular exchange of various metabolites and a vitamin-derived cofactor. Exp. Cell Res. 131: $1-13$.

Foster, R. E., B. W. Connors, and S. G. Waxman (1982) Rat optic nerve: Electrophysiological and anatomical studies during development. Dev. Brain Res. 3: 371-386.

Fulton, B. P., R. Miledi, and T. Takahashi (1980) Electrical synapses between motoneurons in the spinal cord of the newborn rat. Proc. R. Soc. Lond. (Biol.) 208: 115-120.

Goodman, C. S., and N. C. Spitzer (1979) Embryonic development of identified neurones: Differentiation from neuroblast to ncurone. Nature 280:201 214.

Gutnick, M. J., and D. A. Prince (1981) Dye-coupling and possible electrotonic coupling in the guinea pig neocortical slice. Science 211: 67-70.

Gutnick, M. J., B. W. Connors, and B. R. Ransom (1981) Dyecoupling between glial cells in the guinea pig neocortical slice. Brain Res. 213: 486-492.

Hicks, S. P., and C. J. D'Amato (1968) Cell migration to the isocortex in the rat. Anat. Rec. 160: 619-634.

Kaneko, A., Y. Nishimura, M. Tauchi, and K. Shima (1981) Morphological observation of retinal cells presumably made syncytial by an electrode penetration. J. Neurosci. Meth. 1: 299-303.

Knowles, W. D., and P. A. Schwartzkroin (1981) Local circuit synaptic interactions in hippocampal brain slices. J. Neurosci. 1: 318-322.

Knowles, W. D., P. G. Funch, and P. A. Schwartzkroin (1982) Electrotonic and dye-coupling in hippocampal CAl pyramidal cells in vitro. Neuroscience $7:$ 1713-1722.

Loewenstein, W. R. (1981) Junctional intercellular communication: The cell-to-cell membrane channel. Physiol. Rev. 61: 829-913.

Lo Presti, V., E. R. Macagno, and C. Levinthal (1974) Structure and development of neuronal connections in isogenic organisms: Transient gap junctions between growing optic axons and lamina neuroblasts. Proc. Natl. Acad. Sci. U. S. A. 71: 1098-1102.

Lund, R. D., and M. J. Mustari (1977) Development of the geniculocortical pathway in rats. J. Comp. Neurol. 173: 289306.

MacVicar, B. A., and F. E. Dudek (1980) Dye-coupling between CA3 pyramidal cells in slices of rat hippocampus. Brain Res. 196: 494-497.

MacVicar, B. A., and F. E. Dudek (1981) Electrotonic coupling between pyramidal cells: A direct demonstration in rat hippocampal slices. Science 213: 782-785.

MacVicar, B. A., N. Ropert, and K. Krnjevic (1982) Dye-coupling between pyramidal cells of rat hippocampus in vivo. Brain Res. 238: 239-244.

Miller, M. (1981) Maturation of rat visual cortex. I. A quantitative study of Golgi-impregnated pyramidal neurons. J. Neurocytol. 10: 859-878.

Miller, M., and A. Peters (1981) Maturation of rat visual cortex. II. Combined Golgi-electron microscope study of pyramidal neurons. J. Comp. Neurol. 203: 555-573.

Mollgard, K. (1975) Membrane specializations in immature dendrites visualized by freeze-etching. In Golgi Centennial Symposium, M. Santini, ed., pp. 367-377, Raven Press, New York.

Mollgard, K., and M. Moller (1975) Dendrodendritic gap junctions (a developmental approach). Adv. Neurol. 12: 79-89.

Parnavelas, J. G., R. Bradford, E. J. Mounty, and A. R. Lieberman (1978) The development of non-pyramidal neurons in the visual cortex of the rat. Anat. Embryol. 155: 1-14.

Peters, A. (1980) Morphological correlates of epilepsy: Cells in the cerebral cortex. In Antiepileptic Drugs: Mechanisms of Action, G. H. Glaser, J. K. Penry, and D. M. Woodbury, eds., pp. 21-48, Raven Press, New York.

Ramon y Cajal, S. (1911) Histologie du Systeme Nerveux de l'Homme et des Vertebres, Vol. 2, Maloine, Paris.

Roney, K. J., A. B. Scheibel, and G. L. Shaw (1979) Dendritic bundles: Survey of anatomical experiments and physiological theories. Brain Res. Rev. 1: 225-271.

Schuetze, S. M., and D. A. Goodenough (1982) Dye transfer between cells of the embryonic chick lens becomes less sensitive to $\mathrm{CO}_{2}$ treatment with development. J. Cell Biol. 92: 694-705.

Schwarzmann, G., H. Wiegandt, B. Rose, A. Zimmerman, D. Ben-Haim, and W. R. Loewenstein (1981) Diameter of the cell-to-cell junctional membrane channels as probed with 
neutral molecules. Science 213: 551-553.

Shoukimas, G. M., and J. W. Hinds (1978) The development of the cerebral cortex in the embryonic mouse: An electron microscopic serial section analysis. J. Comp. Neurol. 179: 795-830.

Sloper, J. J. (1972) Gap junctions between dendrites in the primate neocortex. Brain Res. 44: 641-646.

Sloper, J. J., and T. P. S. Powell (1978) Gap junctions between dendrites and somata of neurones in the primate sensorimotor cortex. Proc. R. Soc. Lond. (Biol.) 203: 39-47.

Smith, D. E., and N. Moskovitz (1979) Ultrastructure of layer IV of the primary auditory cortex of the squirrel monkey. Neuroscience 4: 349-360.

Spray, D. C., A. L. Harris, and M. V. L. Bennett (1979) Voltage dependence of junctional conductance in early amphibian embryos. Science 204: 432-434.
Stewart, W. W. (1978) Functional connections between cells as revealed by dye-coupling with a highly fluorescent napthalimide tracer. Cell 14: 741-759.

Taylor, C. P., and F. E. Dudek (1982) A physiological test for electrotonic coupling between CA1 pyramidal cells in rat hippocampal slices. Brain Res. 235: 351-357.

Williams, E. H., and R. L. De Haan (1981) Electrical coupling among heart cells in the absence of ultrastructurally defined gap junctions. J. Memb. Biol. 60: 237-248.

Wise, S. P., and E. G. Jones (1978) Developmental studies of thalamocortical and commissural connections in the rat somatic sensory cortex. J. Comp. Neurol. 178: 187-208.

Wolff, J. R. (1978) Ontogenetic aspects of cortical architecture: Iamination. In Architestonics of the Cerebral Cortex, $\mathrm{M}$. Brazier and H. Petsche, eds., pp. 159-173, Raven Press, New York. 